\title{
Reliability-Oriented Design of Electrical Machines: The Design Process for Machines' Insulation Systems MUST Evolve
}

\begin{abstract}
As the world of transport keeps moving towards 'heavier' electrification, the main design objectives in terms of power density and efficiency of system components are resulting ever-more important. On the other hand, transport applications are also very safety critical. The 'extra' stresses being seen by the products, in order to achieve the required performances, are therefore inducing more accelerated degradation in terms of the components' lifetime and reliability. In general, lifetime consumption and degradation of components, such as for insulation systems of electrical machines, is still assessed through 'statistical' methods (i.e. recording the number of imposed cycles until failure of a built prototype). This is of course a very time-consuming and expensive process. In application fields such as automotive and aerospace, these can be the major bottleneck in terms of the development timeline of an electrical product, especially for certification.

This article therefore argues for the development of new processes, based on comprehensive, physics of failure methodologies, that will enable the electrical machine designer to make reliability considerations a main design objective function, right from the very start of the design process. This paper investigates and describes how this advanced philosophy will allow manufacturers to design insulation systems without relying on the outdated, traditional 'safety factors' and over-engineering philosophies.
\end{abstract}

Index Terms - Electrical machines, Insulation systems, Lifetime degradation, Reliability, Physics of Failure

\section{INTRODUCTION}

ELCTRIFICATION of transport is today seeing a research and development push, in the name of reducing emission [1] and climate change issues [2]. Rapidly extending areas are those of the more electric engine and general electrified traction and drives [2]. Various international transport agendas from all the major authorities across the world have identified this as a key technology area. These include on-going research strategies, such as the ACARE FlightPath2050 [3] which falls under the European Union's umbrella, the UK's Low Carbon Vehicle Partnership's transport roadmaps [2], [4] and several Chinese agendas including the Chinese government's twelfth and thirteenth five-year plans.

In this context, electrical machines (EM) represent a key component [5]. Considering the automotive sector, which has been the precursor of most modern electrification programmes, the role of the EM is already critical, where today various market-ready examples already show how high power density, traction EMs are replacing internal combustion engines. With the more electric aircraft (MEA) initiative, an ever-increasing number of aircraft systems are also becoming operated through electrical systems [6], 
[7]. In all these applications, high power (and torque) density ( $\mathrm{kW} / \mathrm{kg})$ and efficient EMs are a primary requirement, as these requirements enable and underpin better system-level operation, such as less fuel consumption and therefore less emissions.

However, a main constraint of these EMs is reliability. Transport applications require systems that are fail-safe, robust and reliable. For EMs, it can be argued that the two major bottlenecks of failure are 1) the bearings and 2) the insulation systems of the windings [8]. Assuming appropriate scheduled maintenance and replacement procedures [9], i.e. if the bearings are adequately lubricated, then the main source of failure in an EM becomes the windings insulation system [10].

The reality however is that the more these EMs are pushed in terms of power density, the more is the probability of failure of their insulation systems. The most common way how to improve their power density is by increasing the electrical stresses in these machines, i.e. either increasing the current density and/or using higher switching frequencies for higher speeds. These electrical stresses automatically evolve into thermal stresses. If the thermal capacity of these insulation systems becomes inadequate to cope with the required operational performances, then the machine is bound to fail very quickly.

On the other hand, regardless of what its power density is, an EM still needs to be certified according to international standards and procedures. EM standards such as the IEC60505:2011 [11] and the IEC 60034-18-41:2014 [12] set the context in terms of the evaluation and qualification of the insulation system. When developed for transport applications, then these EMs also need to comply with standards like the MIL-STD-704F and the D0-178C.

All this indicates that while it is true that power density and efficiency improvements are essential, however, without the appropriate reliability and robustness, then even the best-performing EM will never be certified for a transport application. At this stage it is important to note that the certification processes in use today, which rely on statistical methods based on accelerated lifetesting of finished specimens are very expensive and time-consuming and therefore fast becoming unsustainable. A new approach is therefore required.

This article therefore seeks to challenge the long-standing processes of how EM insulation systems are designed and implemented and also how EMs are evaluated and certified. The authors argue that a radical step-change in how reliability in EMs is assessed and certified is necessary. The article proposes advanced methodologies that address this much-needed direction change and develops a coherent argument as to why the authors believe that the proposed philosophy needs to become the norm across the whole field of EMs, in the near future.

\section{RELIABILITY AND CERTIFICATION OF EMs}

For the development of insulation systems of EMs, there are today two main challenges which demand urgent attention. These are a) the reliance on 'over-engineering' to design robust systems and b) the outdated methodologies by which EMs are assessed and certified. 


\section{A. Design of insulation systems of EMs today}

EMs are in general designed to comply with a pre-set minimum machine winding life. Most common, industrial EMs are expected to survive and operate for approximately 20 to 40 years. In transport applications, EMs are never expected to operate for more than 5 years. These life expectancies are commonly calculated based on the expected lifetime of the EMs' windings. Traditionally, the insulation system design, to accomplish a specified life target, was largely achieved by trial and error. Thus, if a winding design failed, then the EM designer 'simply' added extra insulation in the next iteration or version of that design. Today, to prevent pre-mature failures, heavy 'safety margins' are added immediately to the design, resulting in insulation systems that highly exceed their actual operational requirements. However this also means that safety margins are excessive and can greatly increase the mass and the cost of the EM. This becomes very important when considering the goal of lighter and more cost-effective machines and systems as required for future aircraft and electric vehicles (EV).

\section{B. Certification of Reliability of EMs today}

In terms of assessment and certification, EMs are still assessed through 'statistical' methods (i.e. recording the number of imposed cycles until failure of a built prototype). These methodologies, which have been the same since the 1960s, require a sample of the 'finished' product, which is subjected to various stress-inducing tests and their failure time recorded. This is obviously a very time-consuming and expensive process. For conservative areas such as the transport field, these requirements represent a major bottleneck in terms of the development timeline of an electrical product. Fig. 1 shows a typical development cycle of an aerospace EM today, based on information gathered by the authors, from working with a leading Tier 1 aerospace machine manufacturer. The imbalance between the time required (and therefore cost) for design and for reliability certification can be clearly observed.

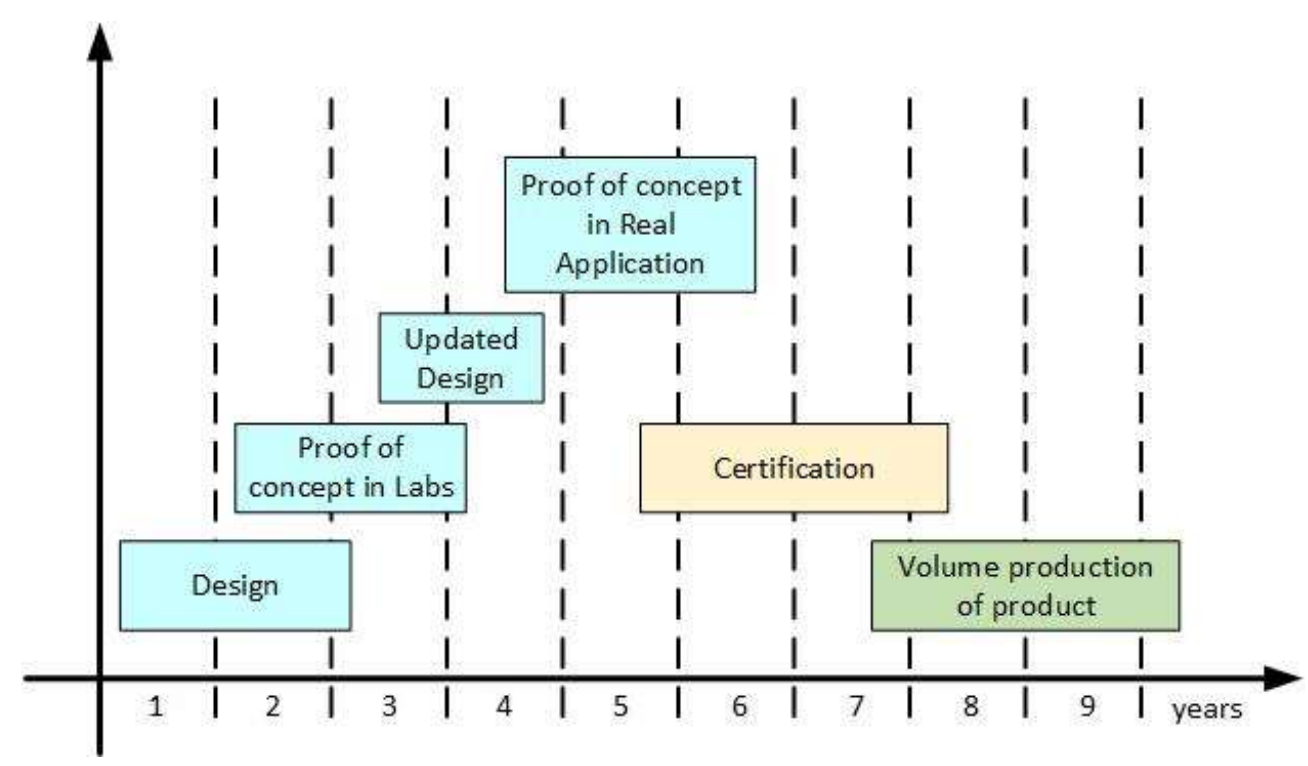

Fig. 1 Typical development cycle for an aerospace EM 


\section{Moving Forward}

A different approach is therefore necessary to go towards the next generation of EMs. Reliability needs to become a design objective function right from the start of the design process. This aim can only be achieved with a new approach and methodology, that combines accuracy with time-efficiency. This paper argues that the only feasible manner in which this can be achieved is through the use of comprehensive, physics of failure (PoF) methodologies that will enable the EM designer to make reliability and lifetime considerations from the very start of the design process. This methodology is based around the development of advanced ageing models that can accurately estimate the lifetime of the winding insulation, assuming that the stresses applied can be quantified and reproduced for validation purposes.

The whole concept of the argument is that the model must be based on a real understanding of the deterioration mechanisms of the insulation system. A real knowledge of the chemical, material and physics phenomena happening in the insulation for particular operation cycles is crucial. Only then will these models be able to predict the 'end of life' time of the insulation system without having to rely on the traditional methods, described above.

A conceptual representation of such a model is given in Fig. 2. The model must be able to define the 'end of life' of the product with a fault distribution and probability curve, such as shown in Fig. 2. The goal of the model is to predict the moment of the failure with a reduced variability than commonly expected today. This is drastically different from traditional approaches that only define a mean time to failure (MTTF) without really considering any variability of the exact moment of failure. The shortcomings of the commonly-applied, reliability handbook techniques are very well described in [13].

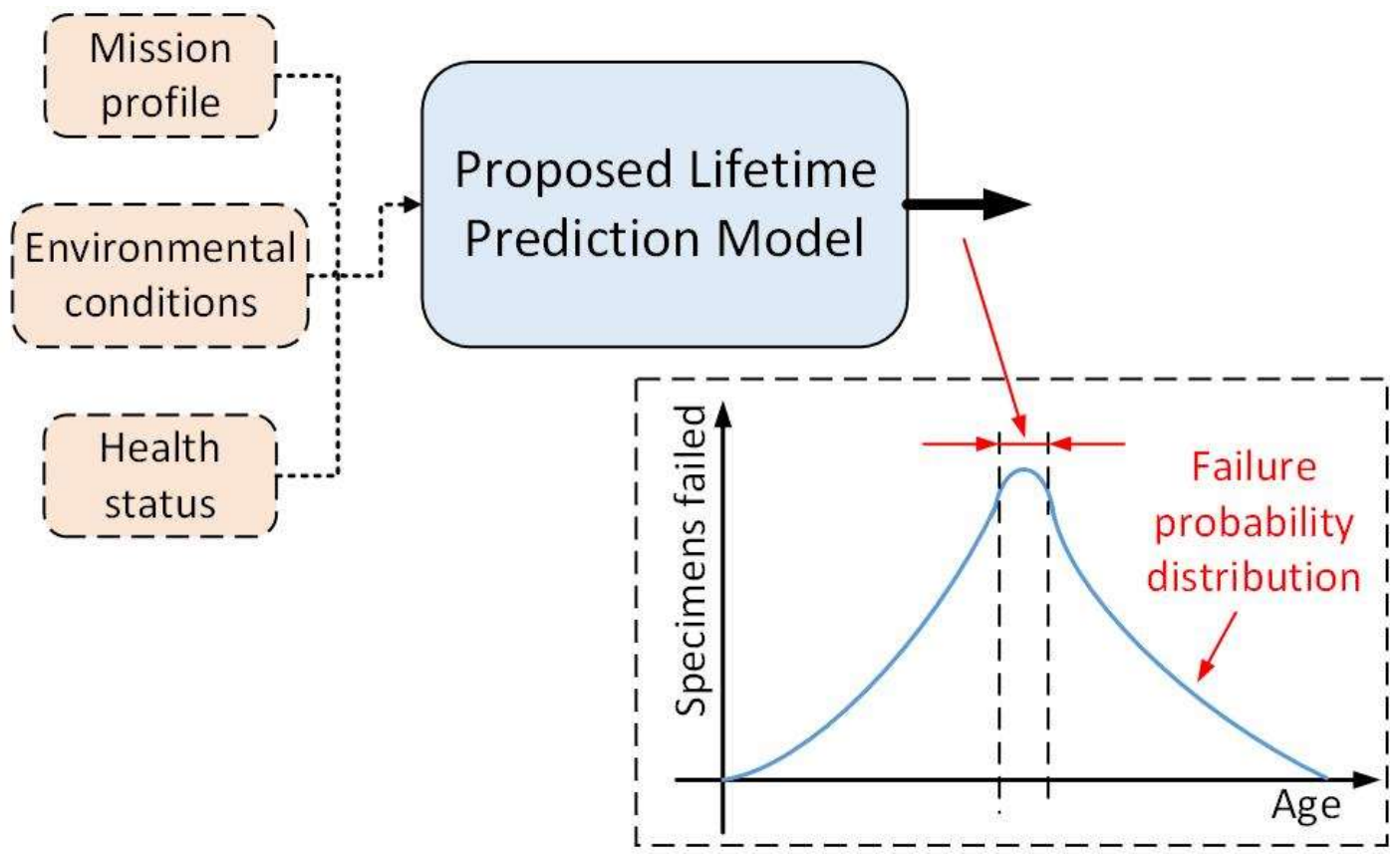

Fig. 2 Conceptual representation of the proposed ageing model(s) 
The model proposed in Fig. 2 can then be seamlessly integrated into the design process of EMs. A conceptual representation of a potential process (one of many 'hopefuls' that can be envisioned) is shown in Fig. 3, where it can be observed that now the 'lifetime model' is giving a direct input to the design of the machine. This is opposed to the traditional method of first designing the machine and then simply checking that the machine survives for some set conditions. Here reliability is considered right from the start and is actually an input to the design process.

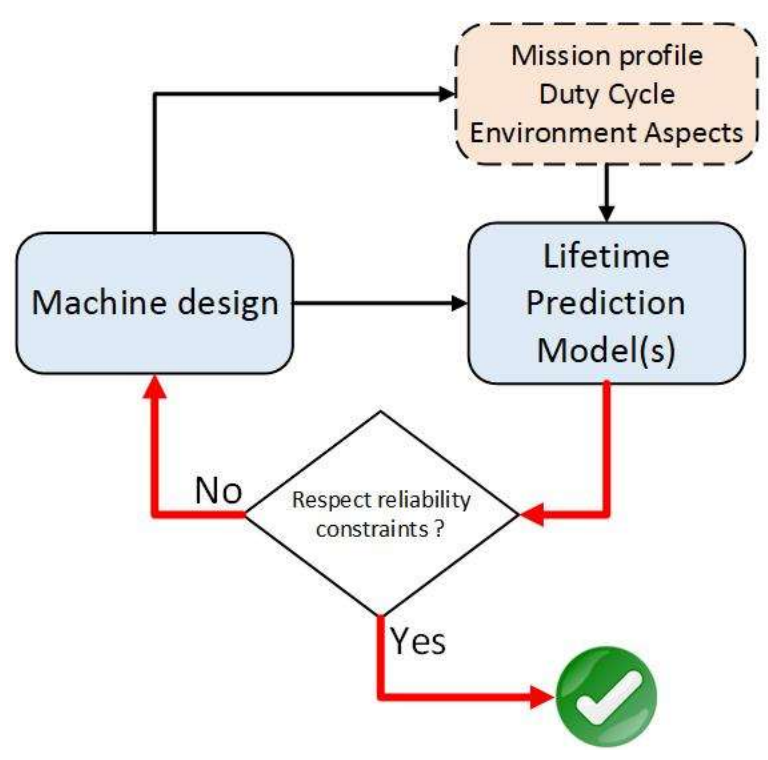

Fig. 3 Ageing model incorporated in the design process of machines

This type of philosophy is today practically inexistent in the standard design processes of EMs. It is perceived that if fully implemented, this methodology will result in

1) Significant reductions (and ultimately the removal) of the need for 'over-engineering' and the use of the traditional 'safety factors' thus leading to improved power densities and cost-effectiveness,

2) Very important reductions of the time required for assessment and certification of EMs, thus leading to reduced development lifecycles, in terms of time.

As a final note, it is very important to note that the ageing models being described here are very different from the failure prediction methods that are in common use today across the world of science and engineering. The common 'fault-tree' methods are based on techniques called the Probability Density Function and Cumulative Density Function of the potential failure happening. These methods are very simplistic functions that go back to the 1950s and do not take into account the development of new technologies. Thus, these assumptions represent a very crude approximation of the reliability and 'cycles to failure' problem. Thus, to be successful, any process based around the concept proposed in Fig. 3 requires modern and accurate, ageing models. It is therefore the authors' opinion that such processes can only be of benefit, if the proposed model(s) in Fig. 2 are based on more advanced methodologies such as detailed PoF techniques. 


\section{UNDERSTANDING TODAY'S METHODS AND THEIR LIMITATIONS}

The 'statistical' methodologies described in Section II, all rely on the availability of a set of 'completed' products that can then be subjected to accelerated lifetime testing, usually by implementing harsh testing regimes on these prototypes until they reach a set 'failure point'. The time to reach this 'failure point' is then called the lifetime of the product. While this process is still the most common methodology in use today, it is also known to be very unreliable and inaccurate [13].

\section{A. Calculating failure today: general components}

In more practical terms, i.e. when any particular product is working in its intended normal operating environment (not subjected to abnormal operating conditions, such as for accelerated lifetime cycling), the lifetime of that component is usually defined as the period of time from the moment when it comes off the production line to the exact time that it fails to produce its required performance. This time window is of course dependent on the particular system application and on the environmental conditions to which it is exposed. During this time, the degradation of the components can be said to depend only on the system and environmental loads.

As mentioned above, the majority of engineering products have traditionally been assessed for robustness through 'statistical' methods, i.e. by recording the number of imposed cycles until failure of a built prototype. Over the last two / three decades, manufacturers have started to realize how costly and time-consuming these old methodologies are and have tried to investigate more modern ways how to understand the real degradation phenomena. Thus, a lot of effort has gone towards improved methods that typically aim to correlate the statistical data from the traditional tests to slightly more advanced degradation models.

However, even the more advanced of these methods, still rely heavily on statistical methods, where the finished product (or specimen of it) is put under multi-stress testing with accelerated life cycles. The specimens are then tested and categorized according to their 'state of health' after every test. A widely adopted statistical tool for the reliability assessment of electrical insulation, (as well as for roller bearings, electronic components, ceramics, capacitors etc.) is the Weibull distribution [14]. The popularity of the Weibull distribution is mainly due to 1) its flexibility in modeling either increasing or decreasing failure rates, 2) its ability to fit data coming from accelerated lifetime tests, in a much simpler manner $[14,15]$ than with exponential, normal and lognormal distributions, 3) it requiring only a small number of samples to be subjected to accelerated aging tests, without compromising the final result's accuracy and 4) its ability to allow data censoring.

Equation (1) describes the Weibull cumulative distribution function, where $\alpha$ is the scale parameter, $t$ is the time to failure, and $\beta$ is the shape parameter. In particular, $\alpha$ is the $63.2 \%$ percentile of failure times, while $\beta$ is inversely proportional to the data scatter, which is directly correlated to the failure times variance.

$$
F(t)=1-\exp \left[-\left(\frac{t}{\alpha}\right)^{\beta}\right]
$$




\section{B. Calculating failure today: machine insulation systems}

EMs are found in various applications, including transport, home appliances and industrial [16]. However, it is machines employed in transport which are particularly demanding in terms of their insulation capability required to withstand high stress level, including electrical, thermal, mechanical and environmental stresses. For these applications, EMs usually operate with a voltage level below $1000 \mathrm{~V}$ (i.e. low voltage EMs) and generally adopt a "random wound" layout and use round enameled magnet wires [8]. The interturn insulation is provided by a thin enamel layer, which is conventionally a Type I insulation (i.e. organic chemical composition).

A number of stresses are responsible for the main aging in electric transportation applications, where a significant level of power density is often required [17]. Indeed, the machine's power to weight ratio is normally limited by the (maximum) stresses at which the insulating materials can operate $[18,19]$. At the same time, EMs for transportation applications need to be outstandingly reliable throughout their whole life. The premature failure of low voltage EMs is generally originated by excessive aging and degradation of the turn to turn insulation [20]. Therefore, a precise knowledge of the turn to turn insulation deterioration level, can allow to predict an EM's time to failure. Some of the common non-destructive tests are the insulation capacitance (IC), insulation resistance [15] and PD detection [21]. For medium voltage machines, comprising mixed organic-inorganic insulating materials (i.e. Type II), several tools can be employed for predicting the insulation's aging/deterioration level $[8,22]$. These techniques can be either offline or on-line. Among the off-line strategies, the tan $\delta$ (or dissipation factor) measurement is frequently implemented for machines and power transformers [23]. If properly implemented, the dissipation factor test can give precise information regarding the insulation status [24], as it can accurately indicate if the insulation is subject to partial discharges (PDs) inception.

If suitable sensors are adopted (e.g. antennas), the on-line PD test can detect the occurrence of PDs in the inter turn insulation [25]. Nonetheless, such measurement does not provide useful information in terms of lifetime assessment/modeling, as the PD inception generally represent the end-of-life point in Type I insulation [26, 27]. In [28], the aging level of a traction motor is assessed via a non-intrusive, online method. The analysed specimens are twisted pairs aged at constant temperature in a ventilated oven. A similar study is proposed in [29] for medium voltage EMs. In this case the aging, deriving from electrical and thermal stresses, of the mainwall insulation is linked with variations of IC, dissipation factor and PD patterns. The thermal aging influence on the IC is also verified in [30], where the samples are twisted pairs and the thermal degradation is associated with the decrement in partial discharge inception voltage (PDIV).

All the above are excellent advances made in the name of understanding the degradation phenomena of EM insulation systems. In fact, the last two decades have resulted in a lot of data and methodologies applicable for this area. However, the main challenges with all the above remain that these methodologies are still focused on only one particular stress at and that the information being achieved is usually not fed back into the development process to inform a full life-time prediction model. 


\section{AdVAncing the State OF the ART}

Novel multi-stress models which can estimate the lifetime of an EM's insulation when simultaneously exposed to several stress types can be proposed and investigated. With an adequate implementation of these models, then an EM can be designed not only in terms of its performance requirements, but also considering the associated reliability and lifetime aspects.

\section{A. Concept of the proposed methodology: Case study}

EMs employed for on-ground transport application, are typically machines designed for high power/torque performance operating under harsh, highly variable, duty cycles, where the main ageing factors that need to be considered are those due to the thermal and thermo-mechanical stresses. For short-time duty applications, the winding temperature of the EM, typically varies between ambient temperature and a maximum temperature reached at the end of the loading period, without ever reaching a steady state value. Since the ageing factors considered in such an application are very temperature dependent, then the main input required by any developed life-time model is the winding temperature profile $\theta(t)$, as function of time $t$. The lifetime of the insulating material under thermal ageing at constant temperature $\theta$, can be modelled by (1), where $L$ is the insulation lifetime under thermal stress at temperature $\theta, L_{0}$ represent the lifetime at a reference temperature $\theta_{0}$, whilst the parameter $B$ is related to the activation energy of the degradation process.

$$
L=L_{0} \cdot \exp \left[-B\left(\frac{1}{\theta_{0}}-\frac{1}{\theta}\right)\right]
$$

This model [31] relates the thermal ageing of the winding to the rate of a temperature dependent chemical reaction, through the use of the Arrhenius equation. To take into account the effects of the thermal cycling (i.e. temperature variation), the ArrheniusDakin law, as given in (2) must be combined to Miner's cumulative damage law [32]. The insulation 'loss of life' during a single activation cycle (i.e. temperature profile depending on the machine's mission) can be calculated as in (3) where $\Delta t_{\text {cycle }}$ is the time duration of the temperature profile and $\theta_{i}(t)$ the vector temperature vs. time. For clarity, the computation of the loss of life fraction, for a generic temperature profile $T P$ is graphically shown in Fig. 4.

$$
L F_{\text {cycle }}=\int_{0}^{\Delta \mathrm{t}_{\text {cycle }}} \frac{d t}{L\left[\theta_{i}(t)\right]}
$$

Therefore, according to Miner's law, the predicted number of cycles to failure can be calculated as in (4). Alternatively, the total life, in a unit measure of time (i.e. hours, days etc...), of the cyclically stressed insulation can be calculate as in (5).

$$
\begin{gathered}
K=1 / L F_{\text {cycle }} \\
L_{\text {tot }}=K \Delta t_{\text {cycle }}
\end{gathered}
$$




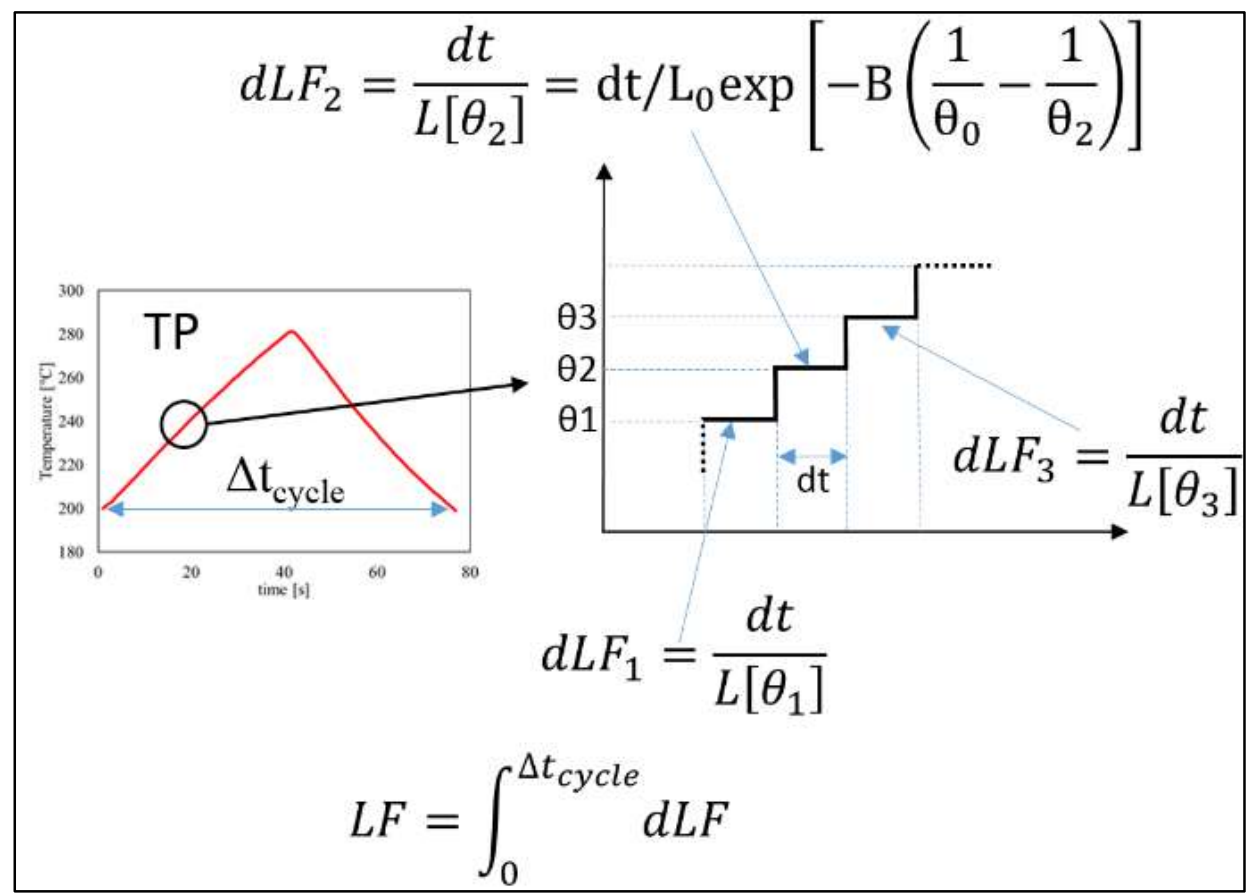

Fig. 4 Computation of the loss of life.

These expressions (3) - (5) were experimentally proven in $[33,34]$ and define a direct relationship between a number of cycles of a particular mission applied to the machine's insulation and that insulation's state of health. These simple, yet elegant expressions can therefore become the key to all the reliability aspects that the machine designer (for a short duty cycle, on-ground application) needs to consider.

Depending on the steepness of the temperature profile (i.e. the temperature gradient) the proposed model might also need to include an additional corrective factor. This is necessary to take into account any potential, thermally-induced mechanical stresses on the insulation, due to mechanical shear between the conductor surface and the insulation. Such a model has been also proposed by the authors in [20], but it is omitted here for brevity reasons.

\section{B. Using the model for design}

It is therefore clear that the model described by (3) - (5) is basically the theoretical definition of the proposed model in Fig. 2. Applying this concept to the design/development process shown in Fig. 3, then very fast qualification of EMs insulation systems will be possible. This will allow the machine designer to remove the need for the traditional safety factors that were historically used to ensure a long life of the machine. The machine designer now will know the cycles to failure of his/her insulation with a much-increased confidence and will design the EM without having to over-engineer the product, allowing for savings in the EM's mass, cost and certification time. 


\section{The Scientific Meaning of SUCh Methodologies}

All the above depends on the capability to define accurate estimations of a machine's lifetime. Considering once again the case study described in Section IV, then to achieve the model described by (3) - (5) and conceptually shown in Fig. 2, certain parameters need to be found through experimental testing of specimens. This method of combining knowledge of degradation mechanisms with data taken from experiments is the basis of the so-called PoF method.

In more practical terms, the life-time model described by (3) - (5) is based on the block scheme illustrated in Fig. 5. From the material characteristics and the mission profile of the drive system (i.e. working cycle, environmental conditions), an accurate analysis of the degradation mechanisms is made. Then, with appropriate life models and the data of the intensity of the degradation mechanism integrated with the information gathered from the sensors, appropriate lifetime prediction can be performed. This prediction can be used to validate existing designs or to reach a predetermined requirement of lifetime. A perceived added advantage of the PoF method is that prognostic and health monitoring procedures can then be used to assess the status of the system when in operation.

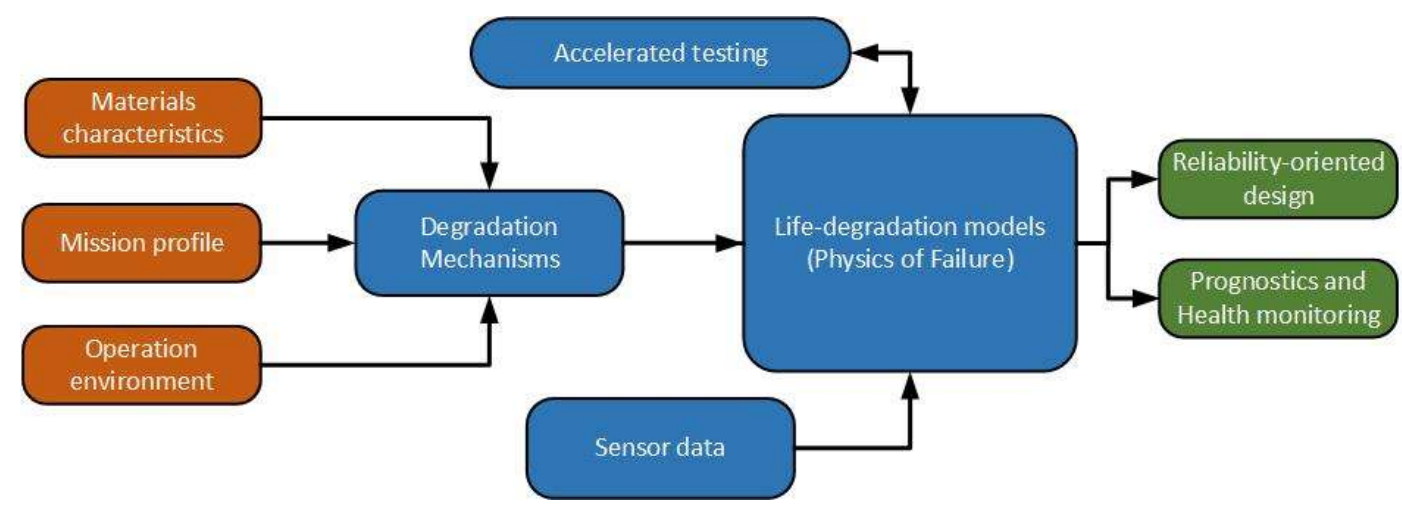

Fig. 5 The basic PoF concept

Thus, having an accurate tool, such as shown in Fig. 2 will result in a step-change in the centuries-old development processes for EMs. The model will address the two main challenges mentioned above and can result in significant advantages as follows.

\section{A. Reducing the weight and cost of EMs}

In the past few decades, it has been recognized that safety margins in the design of the insulation systems of EMs are too excessive. These can greatly increase the mass and the cost of the machine. For example, it was indicated in [35] that a $20 \%$ reduction in the slot-liner insulation thickness in the stator of a large EM will allow the slot area to be reduced. For the same power rating, the split ratio of the EM can then be increased (i.e. a larger air-gap radius), without compromising the EM's mechanical stiffness. Depending on the speed of the EM, the weight of the stator core can be reduced from $23 \%$ to $13 \%$, the copper is decreased from $64 \%$ to $50 \%$ and the mass of the insulation cut down from $57 \%$ to $12 \%$. As the price of an EM is very dependent on the mass of these materials, then the cost is significantly reduced by minimizing the slot liner thickness. However, it is important to note 
that the example given in [35] is not so recent (from 1999) and thus is still loosely based on a trial and error system. Through design processes such as Fig. 3, based on a detailed model such as shown in Fig. 2, which is itself based on detailed PoF methods shown in Fig. 5, then much more significant improvements can be achieved.

In fact, recent literature [36] shows that if an aerospace EM was to be designed by implementing the proposed process of Fig. 3, then the total volume and mass of the EM will be decreased, when opposed to the same EM designed in the traditional manner. This is reflected by the main outcome of [36], which is illustrated in Fig. 6, showing how much smaller a machine (left side machine) can be made (for the same power rating) when the introduced process is used.

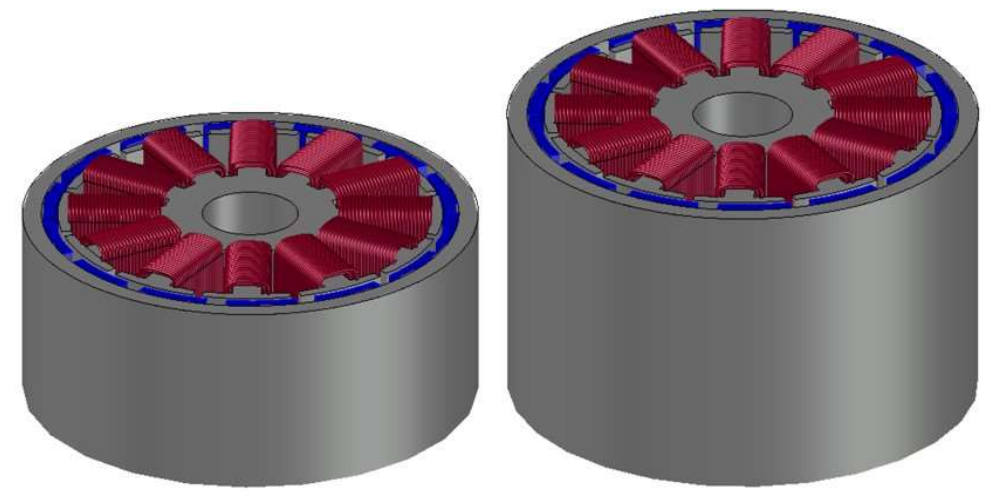

Fig. 6 Benefits of the proposed concepts: Power density [36].

Thus smaller machines for the same power rating (improving the power density) without compromising their reliability values can be achieved. This is done by removing the need for safety-factors in the design. In [36], a $20 \%$ power density (kW/kg) improvement has been achieved.

It can also be argued that such a decrease in mass and volume will result in a reduction in cost. For the case given in [36], a reduction of at least $15 \%$ costs when compared to the original machine was calculated. It is however, very important to note that this needs to be taken as a relative value. It is very difficult to predict costings accurately as the price of raw materials and of manufacturing processes fluctuates heavily with time and availability and several other factors.

\section{B. Reducing the development life-cycle for EMs}

The second main perceived benefit of the proposed methodologies is the potential of reducing the whole development lifecycle time. To be compliant with standards such as the MIL-STD-704F and the D0-178C, machine developers are usually required to plan for long periods of reliability assessments and certification. A typical developement cycle for an aerospace EM is shown in Fig. 1. As mentioned above, these long periods are mainly due to the need for a 'finished prototype' to be tested for long periods of time, once its been manufactured. 
The lifetime prediction models being discussed in this paper will allow for reliability assessments to be done in parallel to the development of the product. In other words, the accelerated life testing required for reliability assessments will be done as an iterative process, as shown in Fig. 5, thus allowing for the development life-cycle of an EM to be reduced significantly. Working with a leading Tier 1, aerospace EM manufacturer, which cannot be named for confidentiality reasons, the authors have performed an investigative study in an attempt to quantify this perceived potential gain for a particular EM range. The main outcome of this study is illustrated in Fig. 7. This work was performed on relatively low voltage, aerospace machines. However, the result shown in Fig. 7 has been generalised in order to adress a wider range of machines than those analysed with the industrial partner.

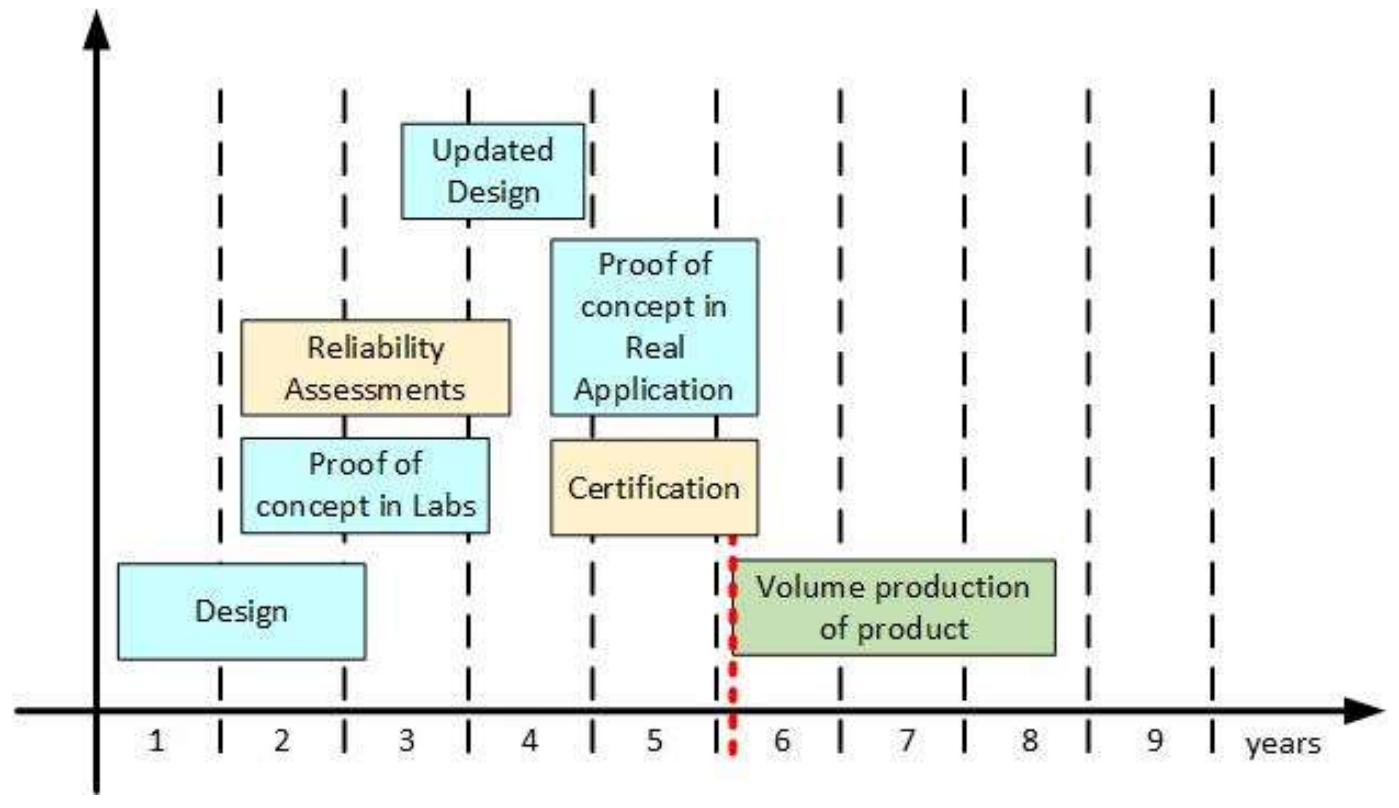

Fig. 7 Benefits of the proposed concepts: Development time cycle

Comparing Fig. 7 with Fig. 1, a considerable improvement in terms of the time required to launch a new product on the market can be achieved. In fact, by implementing the methodologies proposed and discussed in this article, it is predicted that the 'low volume production' period of a new product can start by almost two years earlier than when today's quasi-obsolete development procedures are used.

\section{CONClusion}

The magnitude of the opportunities related to higher performance and more reliable EMs for transport applications can be easily observed from the predicted market growths in the areas related to transport electrification. It is expected that approximately $40 \%$ of all vehicles globally will be electrified by 2025 [1]. In China alone, the market growth of plug-in electric vehicles increased by almost 2000\% between 2009 and 2015, while the Chinese government expects a nation-wide EV presence ranging upwards of 5 million EVs by 2020. 
From an aerospace perspective, there is a growing concern (and related actions and reactions) related to jet fuel emissions predictions. To address this, it is estimated from ongoing market and research studies that electrification activities in aerospace in the next 10 years, will comprise an increase to approximately $50 \%$ of overall more electric aircraft activities [37]. In aerospace applications, the future global market for electrification and electrical drives (including PE) in the civilian area is expected to grow to $\$ 1.78$ billion each year [38].

All this growth does however depend on the industry's capability to remain sustainable and commercially effective in all aspects of the development processes related to EMs and associated systems. The methodologies described in this article can project the industry towards a much-needed step change in how EMs are designed, developed, certified and brought to market. The era of over-engineering, 'trial and error' and statistical techniques is over. Today, every penny counts. Thus, the EM manufacturer that invests in these advanced methods now, will, in a few years, be able to put EMs on the market, that are lighter, more cost effective and in a much shorter time and thus gain an extremely important competitive advantage over the rest of the players in the field.

\section{REFERENCES}

[1] A. Bellini, F. Filippetti, C. Tassoni, and G. Capolino, "Advances in Diagnostic Techniques for Induction Machines," IEEE Transactions on Industrial Electronics, vol. 55, no. 12, pp. 4109-4126, 2008

[2] Z. A. Needell, J. McNerney, M. T. Chang, and J. E. Trancik, "Potential for widespread electrification of personal vehicle travel in the United States," Nature Energy, vol. 1, p. 16112, 2016.

[3] "Flightpath 2050 - Europe's Vision for Aviation, Report of the High Level Group on Aviation Research, EU Commission," Directorate-General for Mobility and Transport; DOI 10.2777/50266; 2011.

[4] "Power Electronics: A strategy for success, UK Government Report for the Department of Business Innovation and Skills," UK Government; 2015.

[5] C. Gerada, M. Galea, and A. Kladas, "Electrical machines for aerospace applications," in 2015 IEEE Workshop on Electrical Machines Design, Control and Diagnosis (WEMDCD), 2015, pp. 79-84.

[6] B. Sarlioglu and C. T. Morris, "More Electric Aircraft: Review, Challenges, and Opportunities for Commercial Transport Aircraft," IEEE Transactions on Transportation Electrification, vol. 1, no. 1, pp. 54-64, 2015.

[7] V. Madonna, P. Giangrande, and M. Galea, "Electrical Power Generation in Aircraft: Review, Challenges, and Opportunities," IEEE Transactions on Transportation Electrification, vol. 4, no. 3, pp. 646-659, 2018

[8] G. C. Stone, I. Culbert, E. A. Boulter, and H. Dhirani, Electrical Insulation for Rotating Machines: Design, Evaluation, Aging, Testing, and Repair. Wiley, 2014.

[9] E. A. Avallone, T. Baumeister, and A. Sadegh, Marks' Standard Handbook For Mechanical Engineers McGraw-Hill Professional, 2006

[10] E. H. Werninck, Electric motor handbook. London: McGraw-Hill Book Company (UK) Limited, 1978.

[11] IEC 60505:2011 Evaluation and qualification of electrical insulation systems, 2011.

[12] IEC 60034-18-41:2014 Rotating electrical machines - Part 18-41: Partial discharge free electrical insulation systems (Type I) used in rotating electrical machines fed from voltage converters - Qualification and quality control tests 2014.

[13] K. C. Kapur and M. Pecht, Reliability Engineering. Hoboken, New Jersey: John Wiley \& Sons, 2014.

[14] W. B. Nelson, Accelerated testing: statistical models, test plans, and data analysis. John Wiley \& Sons, 2009.

[15] V. Madonna, P. Giangrande, and M. Galea, "Evaluation of Strand-to-Strand Capacitance and Dissipation Factor in Thermally Aged Enameled Coils for Low voltage Electrical Machines," IET Science, Measurement \& Technology, Available: https://digital-library.theiet.org/content/journals/10.1049/ietsmt.2019.0071

[16] S. Nuzzo, M. Degano, M. Galea, C. Gerada, D. Gerada, and N. Brown, "Improved Damper Cage Design for Salient-Pole Synchronous Generators," IEEE Transactions on Industrial Electronics, vol. 64, no. 3, pp. 1958-1970, 2017.

[17] C. Zoeller, M. A. Vogelsberger, R. Fasching, W. Grubelnik, and T. M. Wolbank, "Evaluation and Current-Response-Based Identification of Insulation Degradation for High Utilized Electrical Machines in Railway Application," IEEE Transactions on Industry Applications, vol. 53, no. 3, pp. 2679-2689, 2017.

[18] V. Madonna, A. Walker, P. Giangrande, G. Serra, C. Gerada, and M. Galea, "Improved Thermal Management and Analysis for Stator End-Windings of Electrical Machines," IEEE Transactions on Industrial Electronics, vol. 66, no. 7, pp. 5057-5069, 2019.

[19] M. Galea, C. Gerada, T. Raminosoa, and P. Wheeler, "A Thermal Improvement Technique for the Phase Windings of Electrical Machines," IEEE Transactions on Industry Applications, vol. 48, no. 1, pp. 79-87, 2012.

[20] C. Sciascera, M. Galea, P. Giangrande, and C. Gerada, "Lifetime consumption and degradation analysis of the winding insulation of electrical machines," in 8th IET International Conference on Power Electronics, Machines and Drives (PEMD 2016), 2016, pp. 1-5.

[21] J. Yang, J. Cho, S. B. Lee, J. Y. Yoo, and H. D. Kim, "An Advanced Stator Winding Insulation Quality Assessment Technique for Inverter-Fed Machines," IEEE Transactions on Industry Applications, vol. 44, no. 2, pp. 555-564, 2008

[22] G. C. Montanari, "Time behavior of partial discharges and life of type II turn insulation specimens under repetitive impulse and sinusoidal waveforms," IEEE Electrical Insulation Magazine, vol. 33, no. 6, pp. 17-26, 2017.

[23] M. Farahani, H. Borsi, and E. Gockenbach, Study of Capacitance and Dissipation Factor Tip-Up to Evaluate the Condition of Insulating Systems for High Voltage Rotating Machines. 2007, pp. 263-270. 

2001.

[25] A. Cavallini, D. Fabiani, and G. C. Montanari, "A novel method to diagnose PWM-fed induction motors," IEEE Transactions on Dielectrics and Electrical Insulation, vol. 15, no. 5, pp. 1313-1321, 2008.

[26] P. Mancinelli, S. Stagnitta, and A. Cavallini, "Qualification of Hairpin Motors Insulation for Automotive Applications," IEEE Transactions on Industry Applications, vol. 53, no. 3, pp. 3110-3118, 2017.

[27] V. Madonna, P. Giangrande, W. Zhao, H. Zhang, C. Gerada, and M. Galea, "On the Design of Partial Discharge-Free Low Voltage Electrical Machines," presented at the IEMDC 2019 - International Electric Machines \& Drives Conference, 2019.

[28] P. Werynski, D. Roger, R. Corton, and J. F. Brudny, "Proposition of a new method for in-service monitoring of the aging of stator winding insulation in AC motors," IEEE Transactions on Energy Conversion, vol. 21, no. 3, pp. 673-681, 2006.

[29] M. Farahani, E. Gockenbach, H. Borsi, K. Schafer, and M. Kaufhold, "Behavior of machine insulation systems subjected to accelerated thermal aging test," IEEE Transactions on Dielectrics and Electrical Insulation, vol. 17, no. 5, pp. 1364-1372, 2010.

[30] S. Savin, S. Ait-Amar, and D. Roger, "Turn-to-turn capacitance variations correlated to PDIV for AC motors monitoring," IEEE Transactions on Dielectrics and Electrical Insulation, vol. 20, no. 1, pp. 34-41, 2013.

[31] T. W. Dakin, "Electrical Insulation Deterioration Treated as a Chemical Rate Phenomenon," Transactions of the American Institute of Electrical Engineers, vol. 67, no. 1, pp. 113-122, 1948.

[32] M. A. Miner, "Cumulative damage in fatigue," Journal of Applied Mechanics, vol. 12, no. 3, pp. 159-164, 1945.

[33] V. Madonna, P. Giangrande, L. Lusuardi, A. Cavallini, and M. Galea, "Impact of thermal overload on the insulation aging in short duty cycle motors for aerospace," in 2018 IEEE ESARS-ITEC, 2018, pp. 1-6.

[34] V. Madonna, P. Giangrande, L. Lusuardi, A. Cavallini, C. Gerada, and M. Galea, "Thermal overload and insulation aging of short duty cycle, aerospace motors," in press on IEEE transactions on Industrial Electronics, 2019.

[35] B. J. Moore, R. H. Rehder, and R. E. Draper, "Utilizing reduced build concepts in the development of insulation systems for large motors," in Proceedings: Electrical Insulation Conference and Electrical Manufacturing and Coil Winding Conference (Cat. No.99CH37035), 1999, pp. 347-352. V. Madonna, P. Giangrande, and M. Galea, "Introducing Physics of Failure Considerations in the Electrical Machines Design," presented at the IEMDC 2019 - International Electric Machines \& Drives Conference, 2019.

[37] E. Bertolini, S. Eure, P. Hecker, M. Huguet, and F. Sanna-Randaccio, "Clean Sky 2 Impact Assessment", Final Report of the Expert Group of the Clean Sky 2 governing board," European Commission; 2012.

[38] "Electrical Power Systems National Technical Committee (advisory panel for the National Aerospace Technology Strategy, sponsored by the Aerospace, Aviation \& Defence Knowledge Transfer Network)." 